\title{
American Cocker Spaniel
}

National Cancer Institute

\section{Source}

National Cancer Institute. American Cocker Spaniel. NCI Thesaurus. Code C53883.

The American Cocker Spaniel has very long hanging ears, a rounded head, and a profuse, feathered, medium-length coat. The body is compact, with a short back. The coat comes in buff, black, other solid colors, black-and-tan, and parti-color (white with black, white with buff or red, white with black and tan points). Height: 14 1/2 -15 1/2 inches (36.8-38 cm.) Weight: $15-30$ pounds (7-14 kg.) 